\title{
Influence of casein phosphopeptide-amorphous calcium phosphate application, smear layer removal, and storage time on resin-dentin bonding*
}

\author{
Jun LIN ${ }^{1}$, Wei-ying ZHENG ${ }^{1}$, Peng-ruo-feng LIU ${ }^{1}$, Ning ZHANG ${ }^{1}$, Hui-ping LIN $^{1}$, \\ Yi-jing FAN ${ }^{1}$, Xin-hua GU ${ }^{1}$, Oliver VOLLRATH ${ }^{2}$, Christian MEHL ${ }^{\dagger+3}$ \\ ('Department of Stomatology, the First Affiliated Hospital, School of Medicine, Zhejiang University, Hangzhou 310003, China) \\ ('Institute of Medical Informatics and Statistics, University Hospital Schleswig-Holstein, Campus Kiel, 24105 Kiel, Germany) \\ $\left({ }^{3}\right.$ Department of Prosthodontics, Propaedeutics and Dental Materials, Christian-Albrechts University at Kiel, \\ Arnold-Heller-Straße 16, 24105 Kiel, Germany) \\ †E-mail: Christian.Mehl@HarderMehl.de
}

Received Aug. 14, 2013; Revision accepted Feb. 12, 2014; Crosschecked June 20, 2014

\begin{abstract}
The aim of this study is to evaluate the influence of Tooth Mousse (TM) application, smear layer removal, and storage time on resin-dentin microtensile bond strength ( $\mu$ TBS). Dentin specimens were divided into two groups: (1) smear layer covered; (2) smear layer removed using 15\% EDTA for $90 \mathrm{~s}$. In each group, half the specimens were treated once with TM for $60 \mathrm{~min}$. After bonding procedures using a two-step self-etching adhesive (Clearfil SE Bond (CSE); Kuraray Medical, Tokyo, Japan), an all-in-one adhesive (G-Bond (GB); GC Corp, Tokyo, Japan), and a total-etch adhesive (Adper Single Bond 2 (SB); 3M ESPE, St. Paul, MN, USA), the specimens were stored for $3 \mathrm{~d}$ or 6 months in deionized water at $37^{\circ} \mathrm{C}$, and $\mu$ TBS was tested and analyzed. With the exception of SB (no TM application) and GB, the $\mu$ TBS was significantly increased for CSE and SB using EDTA pre-conditioning and $3 \mathrm{~d}$ of storage $(P \leq 0.001)$. Bond strength of GB decreased significantly when using EDTA ( $3 \mathrm{~d}$ storage, $P<0.05$ ). TM application only increased the $\mu$ TBS of GB (no EDTA) and SB (with EDTA) after $3 \mathrm{~d}(P \leq 0.02)$. Comparing the adhesives after $3 \mathrm{~d}$ of storage, CSE exhibited the greatest $\mu$ TBS values followed by GB and SB $(P \leq 0.02)$. The factors of adhesive, EDTA, and TM did not show any significant impact on $\mu$ TBS when specimens were stored for 6 months $(P>0.05)$. The additional application of TM and EDTA for cavity preparation seems only to have a short-term effect, and no influence on $\mu$ TBS of dentin bonds after a period of 6 months.
\end{abstract}

Key words: Tooth Mousse, Ethylenediaminetetraacetic acid (EDTA), Casein phosphopeptide-amorphous calcium phosphate, Smear layer, Bond strength doi: 10.1631 jzus.B1300216

Document code: A

CLC number: R783.1

\section{Introduction}

Dentin hypersensitivity has a prevalence of around 25\% (Que et al., 2010). It is mainly caused by exposed dentin as a result of enamel loss and/or gingival root surface exposure from attrition, abrasion,

\footnotetext{
${ }^{\ddagger}$ Corresponding author

* Project supported by the National Natural Science Foundation of China (Nos. 81271955 and 30973350) and the Zhejiang Provincial Natural Science Foundation of China (No. Y2080338)

(C) Zhejiang University and Springer-Verlag Berlin Heidelberg 2014
}

erosion, or wedge-shaped defects (West et al., 1998; Vanuspong et al., 2002; Pashley et al., 2008). Also, iatrogenically caused dentin sensitivity, after placement of direct or indirect restorations on vital teeth, is a common clinical phenomenon (Swift, 2004; Denner et al., 2007; Berkowitz et al., 2009). Dentin hypersensitivity is possibly provoked by an abnormal flow of dentin tubule fluid due to external stimuli (Pashley et al., 1996).

Agents used to close patent dentinal tubules include fluoride-containing solutions/compounds, oxalates 
and nitrates of potassium, potassium chloride or strontium chloride (Sulieman, 2005), amorphous calcium phosphates (Geiger et al., 2003), resin-based bonding agents, and the placement of restorations (Adebayo et al., 2008b). Casein phosphopeptideamorphous calcium phosphate (CPP-ACP), introduced in the 1990s (Reynolds, 1998), consists of casein phosphopeptides derived from milk proteins that have been reported to bind amorphous calcium phosphate; this forms nanoclusters of CPP-ACP, thereby stabilizing calcium phosphates in solution (Reynolds, 1998; Adebayo et al., 2008b).

CPP-ACP reduces demineralization and enhances remineralization of enamel and dentin by maintaining a high concentration gradient of calcium phosphate on the tooth surface (Reynolds, 1997; 1998). Various studies have successfully used CPP-ACP as a supplement in acidic drinks to reduce erosivity and dentin hypersensitivity and to protect dental hard tissues (Ramalingam et al., 2005; Piekarz et al., 2008; Tantbirojn et al., 2008). Moreover, CPP-ACP also reduces aggressive abrasion and dentin hypersensitivity caused by interproximal enamel reduction (Giulio et al., 2009; Ranjitkar et al., 2009). Additional studies confirmed reports that CPP-ACP can reduce demineralization and enhance remineralization of bovine and human dentin (Oshiro et al., 2007; Rahiotis and Vougiouklakis, 2007; Yamaguchi et al., 2007).

Hypersensitive cervical dentin is mostly associated with a thinner amorphous smear layer and more open and wider tubules than non-sensitive cervical dentin (Absi et al., 1995; Rimondini et al., 1995). Additional loss of intertubular dentin is reported (Rimondini et al., 1995). A uniform amorphous smear layer varying in thickness and containing crystallinecoating debris has been observed on exposed cervical dentin in non-carious cervical lesions (Rimondini et $a l ., 1995)$. The presence and quality of the smear layer affect bonding of self-etching adhesives and may reduce bond strength since the dissolved smear layer components are not rinsed away (Koibuchi et al., 2001; Tani and Finger, 2002; Oliveira et al., 2003). The removal of the smear layer using cavity conditioners before CPP-ACP application is a current topic in the literature, as remaining smear layer could impede penetration of the CPP-ACP paste and subsequently the adhesive resin (Adebayo et al., 2008b).
Few studies report a negligible influence of TM pretreatment and cavity conditioning using self-etch adhesives on bond strength (Adebayo et al., 2008b; Zorba et al., 2010). Based on the usefulness of CPP-ACP as a desensitizer and in the absence of data on bond strength after long-term storage, the aim of this study was to evaluate the influence of CPP-ACP on microtensile bond strength ( $\mu$ TBS) in a two-step self-etching/priming adhesive, an all-in-one adhesive, and a total-etch adhesive to dentin in combination with or without smear layer removal. The nullhypotheses of this study were that CPP-ACP, storage time, and ethylenediaminetetraacetic acid (EDTA) pretreatment have no influence on $\mu$ TBS following a two-step self-etching/priming adhesive, an all-in-one adhesive, and a total-etch adhesive to dentin.

\section{Materials and methods}

\subsection{Tooth preparation}

Seventy-two intact non-carious human third molars were extracted and stored in $0.1 \%(1 \mathrm{~g} / \mathrm{L})$ thymol-saturated isotonic saline solution at $4{ }^{\circ} \mathrm{C}$. The teeth were collected after informed consent under a protocol approved by the Faculty of Dentistry Ethics Committee of Zhejiang University, China. The teeth were equally divided into 3-d and 6-month storage groups. All teeth were used within three months of extraction.

Fig. 1 shows a flow chart of the process from tooth to $\mu$ TBS beam. The occlusal enamel was removed perpendicular to the longitudinal axis of each tooth by a slow-speed diamond saw (Isomet, Buehler Ltd., Lake Bluff, IL, USA) with water cooling. The resulting flat dentin surface was checked with a stereomicroscope (Wild Makroskop M420, Heerbrugg, Switzerland) at $10 \times$ magnification for the absence of enamel. The bonding surfaces were further polished with a 600-grit silicon carbide paper to create a standardized smear layer in mid-coronal dentin (Yang et al., 2006). For all specimens, the dentin was kept wet during these preparations by storage in deionized water or placement on a wet dish. In order to more closely resemble a clinical situation where dentin is normally exposed and hydrated naturally, the apex of the root was not sealed to allow intrusion of the storage media (de Munck et al., 2003). 


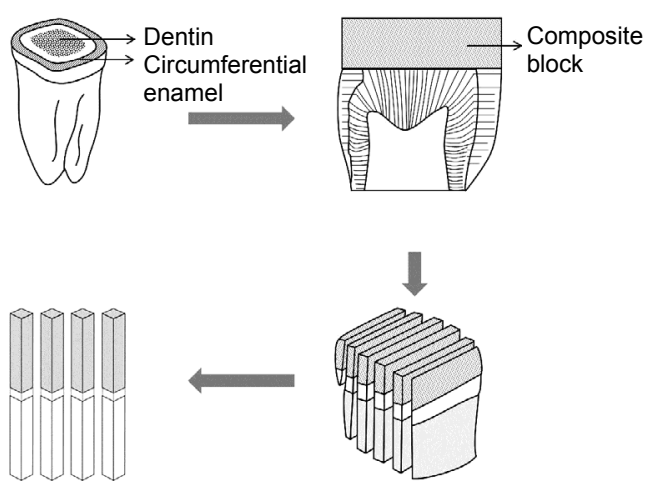

Fig. 1 Flow chart from tooth to specimen showing the design of specimens with the circumferential enamel present and removed

This figure is modified from Lin et al. (2010)

\subsection{Tooth conditioning and bonding procedures}

After smear layer preparation, the short- and long-term storage groups were randomly divided again. In Group 1, the smear layer was left for the subsequent treatment and bonding procedures, while in Group 2 the smear layer was removed using 15\% EDTA for $90 \mathrm{~s}$ and gently rinsing for $15 \mathrm{~s}$. Prior to the bonding procedures, half of the specimens in each group were treated with CPP-ACP paste (Tooth Mousse (TM); GC Corp., Tokyo, Japan). TM was applied by an applicator brush covering the entire dentin surfaces. The TM-treated specimens were placed in a sealed pot at $37{ }^{\circ} \mathrm{C}$ and $(95 \pm 5) \%$ relative humidity for $1 \mathrm{~h}$. The TM paste was then rinsed off in water for $15 \mathrm{~s}$ and the specimens gently dried using water and oil-free air.

The resulting 24 experimental and control groups (three adhesives, EDTA, TM, storage time) were submitted to the bonding protocols using a two-step self-etching adhesive (Clearfil SE Bond (CSE); Kuraray Medical, Tokyo, Japan), an all-in-one adhesive (G-Bond (GB); GC Corp, Tokyo, Japan) and a total-etch adhesive (Adper Single Bond 2 (SB); 3M ESPE, St. Paul, MN, USA) according to the manufacturers' instructions. Composite resin (Valux Plus, $3 \mathrm{M}$ ESPE) was placed directly on the bonded surfaces in $2.5 \mathrm{~mm}$ increments up to a height of $5 \mathrm{~mm}$ with each increment being light-cured for $40 \mathrm{~s}$ (Optilux 500 (550 mW/ $\left.\mathrm{cm}^{2}\right)$; Kerr, Danbury, CT, USA). All chemical compositions and application techniques are shown in Table 1. After completing the adhesive procedures, all specimens were kept in deionized water at $37^{\circ} \mathrm{C}$ for $3 \mathrm{~d}$ or 6 months.

\section{$2.3 \mu$ TBS testing}

After $3 \mathrm{~d}$ or 6 months of storage, the teeth were sectioned into $1.0 \mathrm{~mm} \times 1.0 \mathrm{~mm} \times 10 \mathrm{~mm}$ beams perpendicular to the adhesive/tooth interface using a lowspeed diamond saw according to the non-trimming technique for $\mu$ TBS testing (Sano et al., 1994). Each tooth provided 10-12 beams with the peripheral beams being discarded to reduce variation. Additionally, if stereomicroscope evaluation found beams that were bonded to enamel, these were also discarded. From each of the 24 subgroups, approximately 30 beams per subgroup were used for bond strength evaluation. All beams were glued to the test apparatus with a cyanoacrylate adhesive (Zapit, Dental Ventures of America, Corona, CA, USA) and stressed in tension until failure at a crosshead speed of $1 \mathrm{~mm} / \mathrm{min}$ by using a tensile testing machine (Micro Tensile Tester, Bisco Corporation, Schaumburg, IL, USA).

\subsection{Statistical analysis}

The data were analyzed using a statistical software package (SPSS 18.0, Chicago, IL, USA). Since the $\mu$ TBS data were not distributed normally (Shapiro-Wilks and Kolmogorov-Smirnov test), nonparametric tests were employed. A stratified analysis using Kruskal-Wallis tests followed by Dunn posthoc tests and Mann-Whitney $U$-tests was utilized to analyze the data. Post-hoc testing was adjusted according to Bonferroni-Holm for multiple comparisons. All testing was performed at a confidence level of $95 \%$.

\subsection{Scanning electron microscope (SEM) exami- nation and failure mode analysis}

After $\mu$ TBS testing, the debonded dentin specimens were observed with an SEM (JSM 6400v, JEOL, Tokyo, Japan) to evaluate bond failure modes. The specimens were air-dried for $24 \mathrm{~h}$, gold sputtercoated, and observed at $25 \mathrm{kV}$. Failure modes were classified into one of the following five modes (Fig. 2): A, cohesive failure located in the dentin; $\mathrm{B}$, adhesive failure at the resin/dentin interface; $\mathrm{C}$, mixed adhesive and cohesive failure; $\mathrm{D}$, cohesive failure in the adhesive resin; and $\mathrm{E}$, adhesive failure at the resin/ composite interface. The portion of each failure mode on the debonded dentin surfaces was determined from the SEM micrographs with scale paper and expressed as a percentage of the total bonded surface area for each test group. 
Table 1 Restorative materials used

\begin{tabular}{|c|c|c|c|}
\hline Material & Composition & Batch No. & Application/bonding procedure \\
\hline $\begin{array}{l}\text { Clearfil SE Bond } \\
\text { (CSE; Kuraray }\end{array}$ & $\begin{array}{l}\text { Primer: } 10 \text {-MDP, HEMA, hydrophilic dimethacrylate, } \\
\text { DL-camphorquinone, } N, N \text {-diethanol- } p \text {-toluidine, water; }\end{array}$ & 00923A & $\begin{array}{l}\text { Apply primer and leave for } 20 \mathrm{~s}, \text { dry } \\
\text { thoroughly with mild air flow; }\end{array}$ \\
\hline Medical, Japan) & $\begin{array}{l}\text { Bond: } 10 \text {-MDP, bis-GMA, HEMA, hydrophilic di- } \\
\text { methacrylate, DL-camphorquinone, } N, N \text {-diethanol- } p \text { - } \\
\text { toluidine, silanated colloidal silica }\end{array}$ & 01366A & $\begin{array}{l}\text { Apply bond, gently air-flow, light- } \\
\text { cured for } 10 \mathrm{~s}\end{array}$ \\
\hline $\begin{array}{l}\text { G-Bond (GB; GC } \\
\text { Corp., Japan) }\end{array}$ & $\begin{array}{l}\text { 4-META, urethane dimethacrylate, triethylene glycol } \\
\text { dimethacrylate, acetone, distilled water }\end{array}$ & 0907271 & $\begin{array}{l}\text { Apply bond, leave for } 10 \mathrm{~s} \text {, strongly } \\
\text { air-flow for } 5 \mathrm{~s} \text {, light-cured for } 10 \mathrm{~s}\end{array}$ \\
\hline $\begin{array}{l}\text { Adper Single Bond } \\
2 \text { (SB; 3M ESPE, } \\
\text { USA) }\end{array}$ & $\begin{array}{l}\text { HEMA, bis-GMA, dimethacrylates, methacrylate, func- } \\
\text { tional copolymers (poly acrylic acid and poly itaconic } \\
\text { acid), photoinitiator, ethanol, water }\end{array}$ & N201833 & $\begin{array}{l}\text { Apply for } 15 \mathrm{~s} \text {, gently air-flow for } \\
15 \mathrm{~s} \text {, light-cured for } 10 \mathrm{~s}\end{array}$ \\
\hline $\begin{array}{l}\text { Gluma Etch } 35 \text { Gel } \\
\text { (Heraeus, China) }\end{array}$ & $35 \%$ orthophosphoric acid, $\mathrm{SiO}_{2}$, water, pigment & 562.09 & $\begin{array}{l}\text { Apply for } 15 \mathrm{~s} \text {, rinse for } 10 \mathrm{~s} \text { by } \\
\text { air-water spray }\end{array}$ \\
\hline $\begin{array}{l}\text { Valux Plus ( } 3 \mathrm{M} \\
\text { ESPE, USA) }\end{array}$ & $\begin{array}{l}\text { Bis-GMA, TEGDMA resins, synthetic mineral of zirconia/ } \\
\text { silica, filler }\end{array}$ & N168548 & $\begin{array}{l}\text { Apply to the dentin in three to four } \\
\text { increments up to } 4-5 \mathrm{~mm} \text { thick } \\
\text { and each increment light-cured for } \\
40 \mathrm{~s}\end{array}$ \\
\hline $\begin{array}{l}\text { Tooth Mousse (TM; } \\
\text { GC Corp., Tokyo, } \\
\text { Japan) }\end{array}$ & $\begin{array}{l}\text { Glycerol, } 5 \%-10 \% \text { casein phosphopeptide, amorphous } \\
\text { calcium phosphate, pure water, zinc oxide, sodium } \\
\text { carboxyl, methyl cellulose, xylitol, D-sorbitol, silicon } \\
\text { dioxide, phosphoric acid, titanium dioxide, guar gum, } \\
\text { sodium saccharin, ethyl- } p \text {-hydroxybenzoate, magnesium } \\
\text { oxide, propylene glycol, butyl-p-hydroxybenzoate, } \\
\text { propyl- } p \text {-hydroxybenzoate }\end{array}$ & 090 & $\begin{array}{l}\text { Apply using a micro-brush, cover th } \\
\text { surface of the dentin }\end{array}$ \\
\hline
\end{tabular}

10-MDP: 10-methacryloyloxydecyl dihydrogen phosphate; HEMA: 2-hydroxyethyl methacrylate; bis-GMA: bisphenol A-glycidyl methacrylate; TEGDMA: tetraethylene glycol dimethacrylate

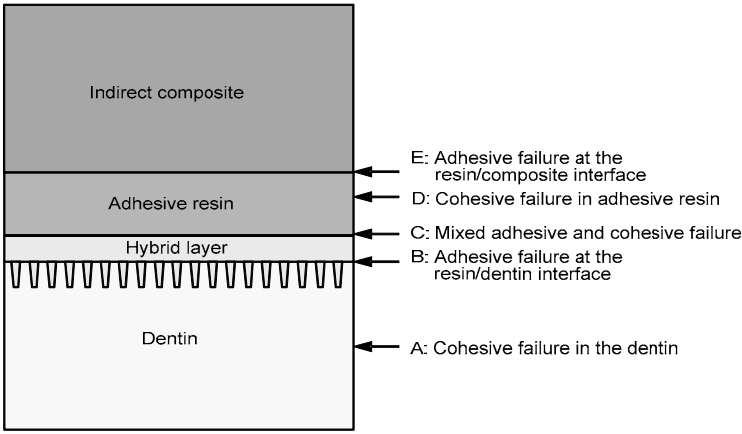

Fig. 2 Definition and location of the failure modes This figure is modified from Lin et al. (2010)

\section{Results}

\section{1 $\mu$ TBS testing}

Since the data were not distributed normally, the median, 25th and 75th percentiles, and the interquartile range (IQR) of the $\mu$ TBS values are presented in Table 2. Tables 3 and 4 present the statistical analysis regarding the influence of the factors of adhesive, EDTA and TM application, and storage time. With the exception of SB (no TM application) and GB, the $\mu$ TBS was significantly increased for CSE and SB by using EDTA pre-conditioning and $3 \mathrm{~d}$ of storage $(P \leq 0.001)$. Bond strength of GB decreased significantly when using EDTA ( $3 \mathrm{~d}$ storage, $P<0.05$ ).
TM application only increased $\mu$ TBS of GB (no EDTA) and SB (with EDTA) after $3 \mathrm{~d}(P \leq 0.02)$. Comparing the adhesives after $3 \mathrm{~d}$ of storage, CSE exhibited the greatest $\mu$ TBS values followed by SB and GB $(P \leq 0.02)$. The factors of adhesive, EDTA, and TM did not show any significant impact on $\mu$ TBS when specimens were stored for 6 months $(P>0.05)$.

\subsection{SEM examination}

The percentages of the fracture modes are recorded in Table 5. The failure mode definitions and examples of failures of representative beams are presented in Figs. 3 and 4.

For specimens bonded with CSE, a nearly even mix between adhesive failure at the adhesive resin/ dentin interface and cohesive failure in the adhesive resin could be observed. A smaller proportion failed adhesively at the adhesive resin/composite interface. For GB specimens, the main failure occurred at the adhesive resin/dentin interface. After 6 months, a shift from cohesive failure in the adhesive resin to adhesive failure at the adhesive resin/composite interface was observed. The main failure mode for SB specimens occurred at the adhesive resin/dentin interface. None of the samples failed cohesively in the dentin. 
Table 2 Microtensile bond strengths ( $\mu$ TBS) of the tested groups to human dentin

\begin{tabular}{|c|c|c|c|c|c|c|c|c|}
\hline \multirow{2}{*}{ Adhesive } & \multirow{2}{*}{$\begin{array}{l}\text { Storage } \\
\text { time }\end{array}$} & \multirow{2}{*}{$\begin{array}{c}\text { EDTA } \\
\text { application }\end{array}$} & \multirow{2}{*}{$\begin{array}{c}\mathrm{TM} \\
\text { application }\end{array}$} & \multirow{2}{*}{$N$} & \multicolumn{4}{|c|}{$\mu \mathrm{TBS}(\mathrm{MPa})$} \\
\hline & & & & & 25th percentile & Median & 75th percentile & IQR \\
\hline \multirow{8}{*}{$\begin{array}{l}\text { Clearfil SE Bond } \\
\text { (CSE) }\end{array}$} & \multirow[t]{4}{*}{$3 \mathrm{~d}$} & \multirow[t]{2}{*}{ No } & No & 25 & 24 & 31 & 42 & 18 \\
\hline & & & With & 28 & 19 & 34 & 49 & 30 \\
\hline & & \multirow[t]{2}{*}{ With } & No & 33 & 30 & 51 & 58 & 28 \\
\hline & & & With & 33 & 49 & 53 & 60 & 11 \\
\hline & \multirow[t]{4}{*}{6 months } & \multirow[t]{2}{*}{ No } & No & 9 & 8 & 14 & 19 & 11 \\
\hline & & & With & 10 & 6 & 19 & 39 & 33 \\
\hline & & \multirow[t]{2}{*}{ With } & No & 22 & 10 & 16 & 34 & 24 \\
\hline & & & With & 26 & 9 & 32 & 46 & 37 \\
\hline \multirow[t]{8}{*}{ G-Bond (GB) } & \multirow[t]{4}{*}{$3 d$} & \multirow[t]{2}{*}{ No } & No & 34 & 13 & 17 & 21 & 8 \\
\hline & & & With & 38 & 16 & 24 & 30 & 14 \\
\hline & & \multirow[t]{2}{*}{ With } & No & 24 & 7 & 14 & 18 & 11 \\
\hline & & & With & 30 & 6 & 9 & 16 & 10 \\
\hline & \multirow[t]{4}{*}{6 months } & \multirow[t]{2}{*}{ No } & No & 19 & 12 & 24 & 41 & 29 \\
\hline & & & With & 19 & 17 & 24 & 34 & 17 \\
\hline & & \multirow[t]{2}{*}{ With } & No & 33 & 14 & 26 & 39 & 25 \\
\hline & & & With & 17 & 16 & 34 & 44 & 28 \\
\hline \multirow{8}{*}{$\begin{array}{l}\text { Adper Single } \\
\text { Bond } 2(\mathrm{SB})\end{array}$} & \multirow[t]{4}{*}{$3 \mathrm{~d}$} & \multirow[t]{2}{*}{ No } & No & 25 & 15 & 25 & 35 & 20 \\
\hline & & & With & 38 & 16 & 23 & 32 & 16 \\
\hline & & \multirow[t]{2}{*}{ With } & No & 36 & 20 & 28 & 37 & 17 \\
\hline & & & With & 37 & 29 & 35 & 41 & 12 \\
\hline & \multirow[t]{4}{*}{6 months } & \multirow[t]{2}{*}{ No } & No & 20 & 8 & 14 & 51 & 43 \\
\hline & & & With & 23 & 9 & 19 & 35 & 26 \\
\hline & & \multirow[t]{2}{*}{ With } & No & 31 & 13 & 29 & 55 & 42 \\
\hline & & & With & 26 & 13 & 24 & 33 & 20 \\
\hline
\end{tabular}

$N$ : number of beams stressed in tension until failure. Since the data were not distributed normally, the median and 25 th/75th percentiles and the interquartile range (IQR) are shown. Decimals are rounded up or down to the next number

Table 3 Analyzing the influence of EDTA cavity conditioning on bond strength using pair-wise Mann-Whitney $U$-tests with factors of adhesive, storage time, and Tooth Mousse (TM) application held constant

\begin{tabular}{|c|c|c|c|c|c|}
\hline \multirow{2}{*}{ Adhesive } & \multirow{2}{*}{ Group } & \multirow{2}{*}{$\begin{array}{c}\mathrm{TM} \\
\text { application }\end{array}$} & \multirow{2}{*}{$\begin{array}{c}\text { EDTA } \\
\text { application }\end{array}$} & \multicolumn{2}{|c|}{ No EDTA vs. with EDTA } \\
\hline & & & & $3 \mathrm{~d}$ & 6 months \\
\hline \multirow{4}{*}{$\begin{array}{l}\text { Clearfil SE-Bond } \\
\text { (CSE) }\end{array}$} & CSE1 & No & No & $P<0.001^{*}$ & $P=0.361$ \\
\hline & CSE3 & No & With & & \\
\hline & CSE2 & With & No & $P<0.0001^{*}$ & $P=0.217$ \\
\hline & CSE4 & With & With & & \\
\hline \multirow{4}{*}{ G-Bond (GB) } & GB1 & No & No & $P=0.083$ & $P=0.974$ \\
\hline & GB3 & No & With & & \\
\hline & GB2 & With & No & $P<0.0001^{*}$ & $P=0.289$ \\
\hline & GB4 & With & With & & \\
\hline \multirow{4}{*}{$\begin{array}{l}\text { Adper Single Bond } 2 \\
\text { (SB) }\end{array}$} & S1 & No & No & $P=0.477$ & $P=0.125$ \\
\hline & S3 & No & With & & \\
\hline & S2 & With & No & $P<0.0001^{*}$ & $P=0.616$ \\
\hline & S4 & With & With & & \\
\hline
\end{tabular}

\footnotetext{
${ }^{*}$ Statistically significant results at $P<0.05$
} 
Table 4 Analyzing the influence of casein phosphopeptide-amorphous calcium phosphate (CPP-ACP) application (Tooth Mousse (TM), vertical analysis) with factors of adhesive, storage time, and EDTA application held constant and the influence of storage time (horizontal analysis) with factors of adhesive, EDTA, and TM application held constant on bond strength using pair-wise Mann-Whitney $U$-tests

\begin{tabular}{|c|c|c|c|c|c|c|}
\hline \multirow{2}{*}{ Adhesive } & \multirow{2}{*}{ Group } & \multirow{2}{*}{$\begin{array}{c}\text { EDTA } \\
\text { application }\end{array}$} & \multirow{2}{*}{$\begin{array}{c}\mathrm{TM} \\
\text { application }\end{array}$} & \multicolumn{2}{|c|}{ No TM vs. with TM } & \multirow{2}{*}{$3 \mathrm{~d}$ vs. 6 months } \\
\hline & & & & $3 \mathrm{~d}$ & 6 months & \\
\hline \multirow{4}{*}{$\begin{array}{l}\text { Clearfil SE-Bond } \\
\text { (CSE) }\end{array}$} & CSE1 & No & No & $P=0.829$ & $P=0.952$ & $P=0.001^{*}$ \\
\hline & CSE2 & No & With & & & $P=0.059$ \\
\hline & CSE3 & With & No & $P=0.207$ & $P=0.064$ & $P<0.0001^{*}$ \\
\hline & CSE4 & With & With & & & $P<0.0001^{*}$ \\
\hline \multirow[t]{4}{*}{ G-Bond (GB) } & GB1 & No & No & $P=0.007^{*}$ & $P=0.670$ & $P=0.025^{*}$ \\
\hline & GB2 & No & With & & & $P=0.554$ \\
\hline & GB3 & With & No & $P=0.086$ & $P=0.347$ & $P=0.002^{*}$ \\
\hline & GB4 & With & With & & & $P=0.001^{*}$ \\
\hline \multirow{4}{*}{$\begin{array}{l}\text { Adper Single Bond } 2 \\
\text { (SB) }\end{array}$} & SB1 & No & No & $P=0.762$ & $P=0.947$ & $P=0.458$ \\
\hline & SB2 & No & With & & & $P=0.453$ \\
\hline & SB3 & With & No & $P=0.014^{*}$ & $P=0.280$ & $P=0.878$ \\
\hline & SB4 & With & With & & & $P=0.002^{*}$ \\
\hline
\end{tabular}

${ }^{*}$ Statistically significant results at $P<0.05$

Table 5 Failure modes after storage of $3 \mathrm{~d}$ or 6 months

\begin{tabular}{cccccccc}
\hline \multirow{2}{*}{ Adhesive } & EDTA & TM & \multicolumn{5}{c}{ Failure mode of 3 d/6 months (\%) } \\
\cline { 5 - 8 } & application & application & A & B & C & D & E \\
\hline Clearfil SE-Bond & No & No & $0 / 0$ & $36 / 15$ & $1 / 2$ & $44 / 70$ & $19 / 13$ \\
(CSE) & No & With & $0 / 0$ & $39 / 50$ & $2 / 2$ & $59 / 9$ & $0 / 39$ \\
& With & No & $0 / 0$ & $38 / 52$ & $1 / 2$ & $47 / 38$ & $14 / 8$ \\
& With & With & $0 / 0$ & $35 / 41$ & $2 / 1$ & $44 / 36$ & $19 / 22$ \\
G-Bond (GB) & No & No & $0 / 0$ & $86 / 64$ & $2 / 1$ & $12 / 15$ & $0 / 20$ \\
& No & With & $0 / 0$ & $58 / 58$ & $2 / 3$ & $40 / 14$ & $0 / 25$ \\
Adper Single Bond 2 & With & No & $0 / 0$ & $78 / 42$ & $1 / 2$ & $21 / 24$ & $0 / 32$ \\
(SB) & With & With & $0 / 0$ & $94 / 82$ & $1 / 2$ & $5 / 11$ & $0 / 5$ \\
& No & No & $0 / 0$ & $75 / 52$ & $2 / 12$ & $16 / 36$ & $7 / 0$ \\
& No & With & $0 / 0$ & $84 / 43$ & $1 / 10$ & $15 / 47$ & $0 / 0$ \\
& With & No & $0 / 0$ & $89 / 49$ & $2 / 5$ & $9 / 46$ & $0 / 0$ \\
& With & With & $0 / 0$ & $81 / 43$ & $1 / 4$ & $11 / 45$ & $7 / 8$ \\
\hline
\end{tabular}

\section{Discussion}

In earlier research, $\mathrm{TM}$ was shown to reduce demineralization and enhance remineralization of dentin, thereby suggesting its use as a desensitizer (Oshiro et al., 2007; Rahiotis and Vougiouklakis, 2007). Only a few studies have examined the influence of TM on bond strength using different testing set-ups, and samples were mostly stored in deionized water for $24 \mathrm{~h}$ or less (Adebayo et al., 2007; Giulio et al., 2009; Silva-Júnior et al., 2011; Borges et al., 2013). One of the aims of the current study was to evaluate the long-term effects of TM and EDTA pretreatment on $\mu$ TBS. The null-hypotheses of this study had to be rejected, since the choice of adhesive and EDTA and TM pretreatment influenced the $\mu$ TBS. Since the data were not distributed normally, interactions of the factors were not tested.

Several studies suggest that sensitive dentin mostly occurs on non-carious cervical lesions on buccal and lingual surfaces of anterior teeth (Tyas, 1995; Osborne-Smith et al., 1999; Adebayo et al., 2008b). Premolar and molar involvement during grinding can lead to hypersensitive non-carious cervical 

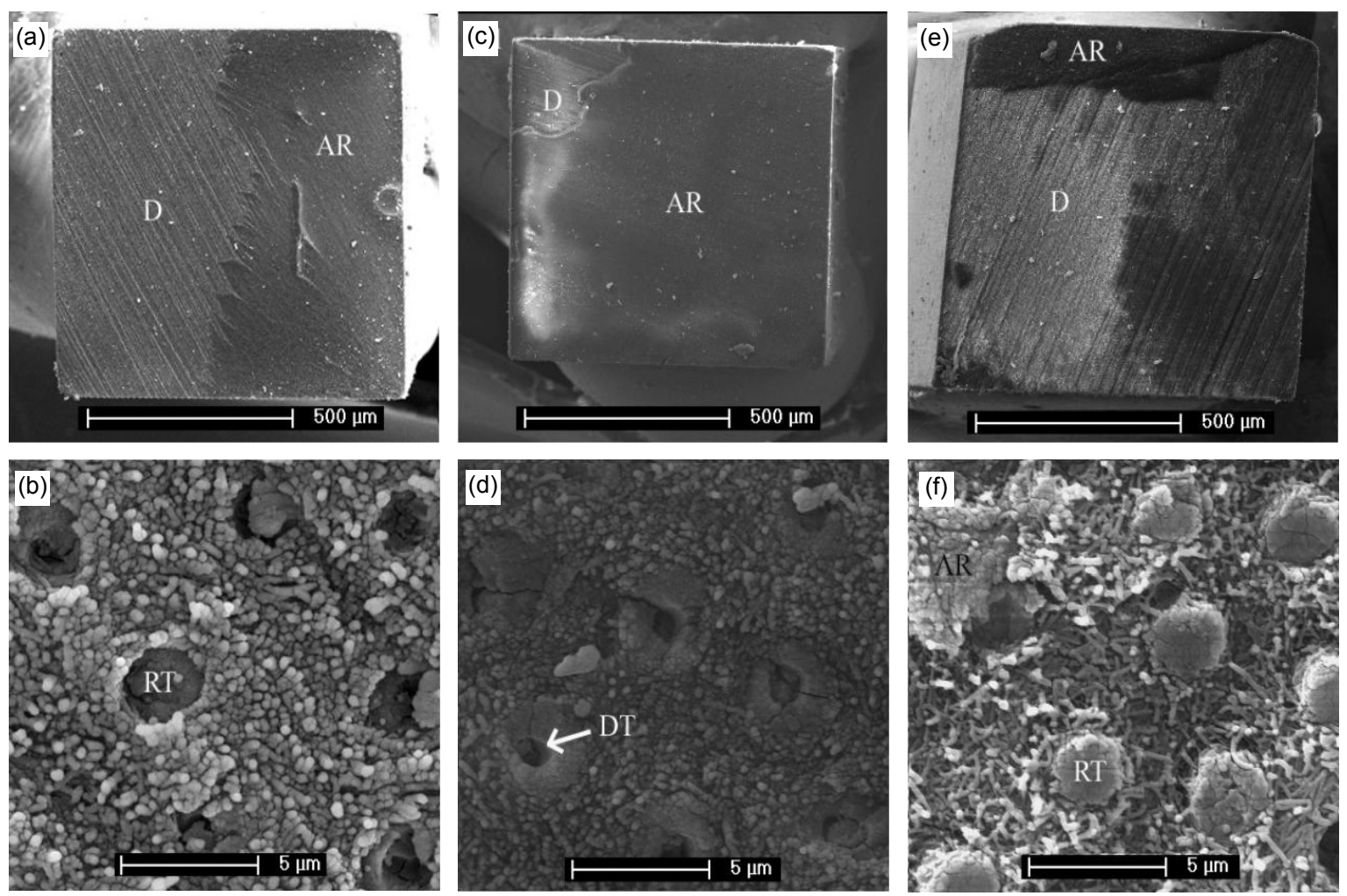

Fig. 3 Representative SEM photographs showing the dentinal side of representative beams after 3-d storage without EDTA and TM treatment

$(a, b)$ Debonded CSE specimens and a mixed adhesive (D: dentin) and cohesive (AR: adhesive resin) failure show some resin tags (RTs) remaining firmly embedded in the tubules, but also some dentin tubules (DTs) only partially closed with resin. No evidence of dentin fibers can be observed, since they remain covered by the smear layer. (c, d) Debonded GB specimens, just like CSE, show a mixed adhesive/cohesive failure and the same mix of completely and only partially closed DTs. Additionally, smear layer and peritubular dentin without collagen fibers are evident. (e, f) Consequences of a different concept regarding the smear layer can be observed. Since phosphoric acid is used for the Adper SB system, the smear layer is dissolved completely, resulting in visible collagen fibers and enabling the AR to enter the DTs and form RTs

lesions in that area (Ommerborn et al., 2007; Tokiwa et al., 2008). As it is difficult to obtain non-carious teeth with cervical lesions, the current study used extracted molars with the anticipation that the degree of opening of the dentinal tubules and the smear layer density obtained would be little different from the morphology of hypersensitive dentin of naturally occurring cervical lesions (Adebayo et al., 2008b). Bonding to dentin was carried out with and without prior smear layer removal before treatment with CPP-ACP paste in an attempt to simulate the clinical situation obtained on exposed cervical dentin lesions (Adebayo et al., 2008b). In this situation, a thin smear layer may cover the dentin surface as in natural lesions (Rimondini et al., 1995; Koibuchi et al., 2001; Adebayo et al., 2008b).
Self-etching adhesives simplify the bonding process by reducing the number of application steps and thus reduce treatment time (Tay and Pashley, 2002). All-in-one adhesives further simplify the bonding process. However, optimizing speed and efficiency should be accomplished without major trade-offs in the quality or durability of resin bonds (Tay and Pashley, 2002), but recent results suggest that time-saving systems may be disadvantageous with regard to bond strength (Oliveira et al., 2003; Perdigao et al., 2006; Lin et al., 2013).

As the results of this study revealed nonparametric data and a wide IQR, operator experience could have had an impact on results (Simonetti et al., 2006; Giachetti et al., 2011). While self-etching adhesive systems were refractory to operator experience 

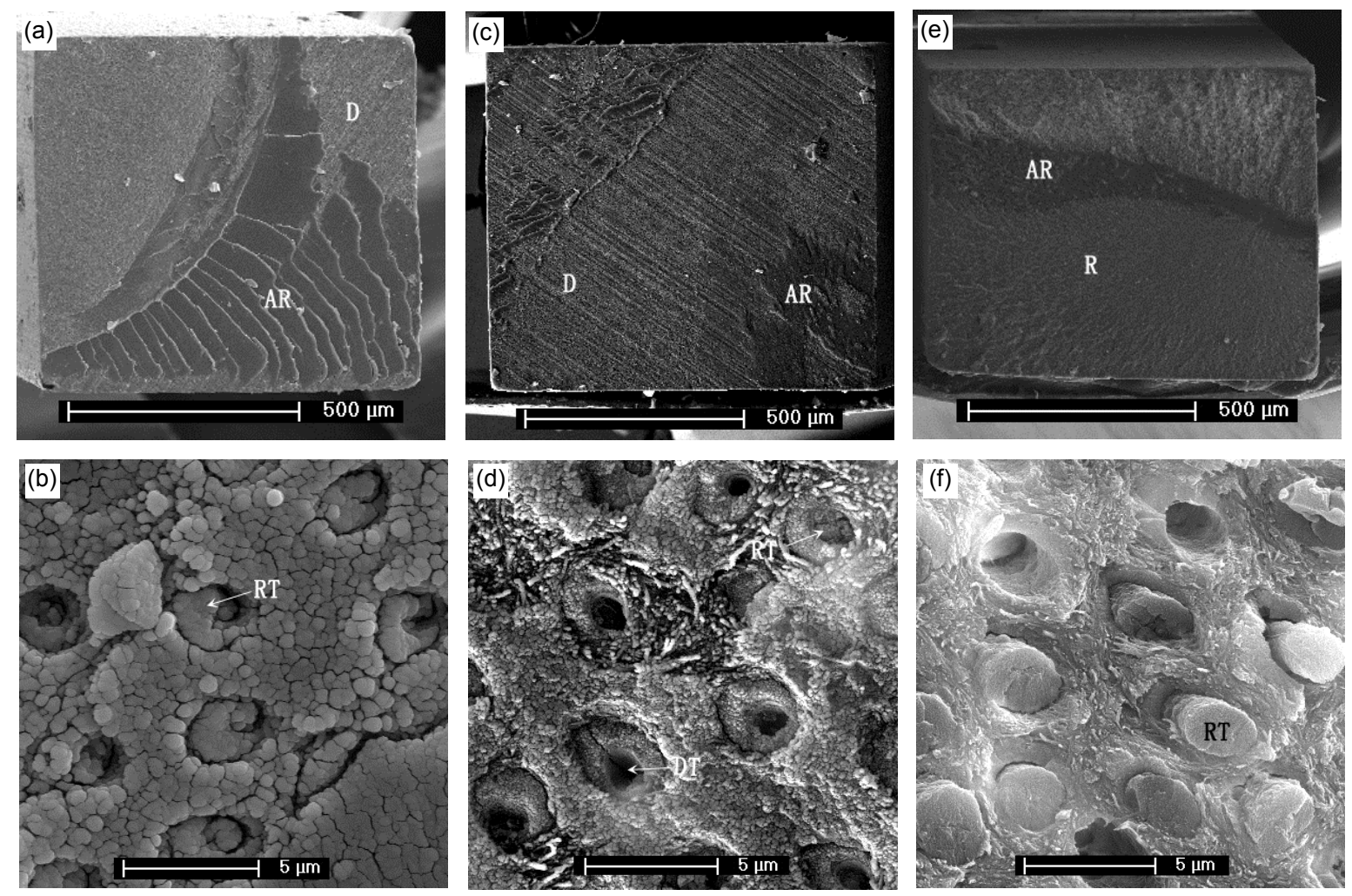

Fig. 4 Representative SEM photographs showing the dentinal side of representative beams after 6-month storage without EDTA and TM treatment

(a, b) Debonded CSE specimens show similar effects to the 3-d storage photographs (Fig. 3b). No evidence of dentin (D) fibers can be observed, since they remain covered by the smear layer. (c, d) In comparison, the 3-d storage debonded GB specimens show a mixed adhesive failure, but here intertubular collagen fibers are evident. (e, f) The Adper SB system exhibits the same working mechanism as already described in Fig. 3 with evident collagen fibers and completely closed tubule orifices forming resin tags (RTs). R: resin; AR: adhesive resin; DT: dentin tubule

(Simonetti et al., 2006; Giachetti et al., 2011), bond strength of a total-etching adhesive system correlated to user experience (Adebayo et al., 2008a; Giachetti et al., 2011). Hence, in the current study, the laboratory workers were briefed and trained. However, the learning curve of the researchers can only partially explain the variations in the performance of the adhesive resins.

Three major factors influence bond strength: first, the infiltration depth of adhesive resin in the dentin (Marshall et al., 1997; Adebayo et al., 2010); second, the degree of polymerization of the adhesive resin (Kanehira et al., 2006); and third, the chemical bonding of the functional monomer (e.g., 10methacryloyloxydecyl dihydrogen phosphate (10MDP), 4-methacryloyloxyethyl trimellitic anhydride (META)) to hydroxyapatite (Yoshida et al., 2004). Comparing the three adhesives in the current study, CSE seemed to infiltrate the residual smear layer best without destroying the collagen network, while GB exhibited only partial infiltration of the tubule network (Figs. 3 and 4) (Adebayo et al., 2010). SB specimens showed the same amount of tubule network infiltration as CSE, but a large percentage (between $80 \%$ and $90 \%$ ) failed at the adhesive resin/ dentin interface. There are several possible explanations, including over-drying, over-etching, over-wetting of the collagen network, or water-induced hydrolysis of the hybrid layer. In this study, it appeared that the collagen network in contact with the adhesive was mechanically or chemically compromised.

With regard to the degree of polymerization of the adhesive resins, it seems that simplified adhesives exhibited a lower extent of polymerization and showed more incomplete polymerization, even after prolonged light curing (Cadenaro et al., 2005). Although no pulpal pressure was applied (Lin et al., 2010), permeability, and thus water entrapment 
within the hybrid layer, related inversely to the degree of polymerization (Tay et al., 2002; Cadenaro et al., 2005). Both permeability of the hybrid layer and lesser polymerization could have led to a mechanical weakening of the bond between SB/GB and dentin.

The third point, the chemical bonding of the functional monomers (e.g., 10-MDP, 4-META, 2-hydroxyethyl methacrylate (HEMA)) to hydroxyapatite could additionally be of importance to explain the results in the current study (Yoshida et al., 2004). Recently, HEMA-free one-step adhesives have been developed, since HEMA is notorious for its high allergenic potential (allergic reaction type IV) (Katsuno et al., 1996; Paranjpe et al., 2005; van Landuyt et al., 2008). These HEMA-free adhesives generally contain a dentin adhesion-promoting monomer, such as 4-META or 10-MDP. It now seems to be established that one of the most efficient functional groups is 10 -MDP, followed by 4-META and then HEMA (CSE=10-MDP; GB=4-META; SB=HEMA) (Tsuchimoto et al., 2006; Iwai et al., 2013). CSE contains the functional monomer 10-MDP, which contributes to dentin bonding by forming ionic chemical bonds with surface calcium ions in dentin crystallites (Dabsie et al., 2012). In a comparative study, the interfacial ultrastructure remained unchanged for 10-MDP after 100000 thermal cycles, while that of 4-META contained voids and lessdefined collagen and thus seemed to have a less stable chemical bonding potential (Inoue et al., 2005).

The main components of the smear layer are hydroxyapatite and denatured collagen which cover the dentin surface and reduce up to $80 \%$ of the dentin permeability (Pashley et al., 1978). EDTA is a mild acid that forms strong complexes with $\mathrm{Ca}^{2+}$. It retains the mineral phase of dentin, but removes the smear layer, thus enhancing the permeation and the chemical reaction of adhesive and dentin (Monticelli et al., 2008). In general, on account of the use of EDTA, the depth of demineralization decreased, the hybrid layers were thinner, the permeation of resin monomers was better, and the $\mu \mathrm{TBS}$ increased (Sauro et al., 2009; 2010). However, conventional theories can hardly explain why $15 \%$ EDTA pretreatment could reduce the bond strength of GB.

With regard to TM application, the general tendency seems to be that TM could be slightly beneficial for $\mu \mathrm{TBS}$ when using self-etching adhesives
(Adebayo et al., 2008b; Sattabanasuk et al., 2009; Silva-Júnior et al., 2011), but should not be applied when using etch-and-rinse adhesives (Sattabanasuk et $a l ., 2009)$. It is assumed that the chemical reaction between $\mathrm{Ca}^{2+}$ in TM and the functional monomer of adhesive resin increases bond strength to dentin to some extent (Sattabanasuk et al., 2009). In the current study, only two out of six experimental groups showed a significant increase in $\mu$ TBS when using TM pretreatment and storage for $3 \mathrm{~d}$. After storage of 6 months no significant influence could be observed, indicating that the long-term effect of TM application seems to be negligible.

However, regardless of all differences in working mechanisms and chemical composition, after 6month storage in water, no significant differences could be found between the adhesive resins. In contrast to three-step etch-and-rinse adhesives, the bond strength to dentin of both one-step and two-step self-etch adhesives decreased after 6 months of water storage in a comparative study (van Landuyt et al., 2010). The overall significant reduction in bond strength after 6-month storage in the current study could be due to factors such as insufficient polymerization, water-uptake, and subsequent plasticization, water- and enzyme-induced nanoleakage, and/or the presence of voids due to phase-separation or osmosis; these demonstrate currently unsolved issues of bonding resin to dentin (Abdalla and Feilzer, 2008; van Landuyt et al., 2010).

\section{Conclusions}

Initially, the tested adhesive resins showed significantly different $\mu$ TBS, but after 6-month storage no significant differences could be found. TM treatment for hypersensitive teeth can be used clinically without compromising the bond strength of a self-etching two-step adhesive resin, an all-in-one adhesive resin, and a total-etch one-step adhesive in the long term. EDTA preconditioning had no significant long-term impact on bond strength.

\section{Compliance with ethics guidelines}

Jun LIN, Wei-ying ZHENG, Peng-ruo-feng LIU, Ning ZHANG, Hui-ping LIN, Yi-jing FAN, Xin-hua GU, Oliver VOLLRATH, and Christian MEHL declare that they have no conflict of interest. 
This article does not contain any studies with human or animal subjects performed by any of the authors.

\section{References}

Abdalla, A.I., Feilzer, A.J., 2008. Four-year water degradation of a total-etch and two self-etching adhesives bonded to dentin. J. Dent., 36(8):611-617. [doi:10.1016/j.jdent. 2008.04.011]

Absi, E.G., Addy, M., Adams, D., 1995. Dentine hypersensitivity: uptake of toothpastes onto dentine and effects of brushing, washing and dietary acid-SEM in vitro study. J. Oral Rehabil., 22(3):175-182. [doi:10.1111/j.13652842.1995.tb01561.x]

Adebayo, O.A., Burrow, M.F., Tyas, M.J., 2007. Effects of conditioners on microshear bond strength to enamel after carbamide peroxide bleaching and/or casein phosphopeptideamorphous calcium phosphate (CPP-ACP) treatment. $J$. Dent., 35(11):862-870. [doi:10.1016/j.jdent.2007.08.007]

Adebayo, O.A., Burrow, M.F., Tyas, M.J., 2008a. Bond strength test: role of operator skill. Aust. Dent. J., 53(2): 145-150. [doi:10.1111/j.1834-7819.2008.00024.x]

Adebayo, O.A., Burrow, M.F., Tyas, M.J., 2008b. Dentine bonding after CPP-ACP paste treatment with and without conditioning. J. Dent., 36(12):1013-1024. [doi:10.1016/j. jdent.2008.08.011]

Adebayo, O.A., Burrow, M.F., Tyas, M.J., 2010. Resindentine interfacial morphology following CPP-ACP treatment. J. Dent., 38(2):96-105. [doi:10.1016/j.jdent. 2009.09.007]

Berkowitz, G.S., Horowitz, A.J., Curro, F.A., et al., 2009. Postoperative hypersensitivity in class I resin-based composite restorations in general practice: interim results. Comp. Cont. Educ. Dent., 30(6):356-358, 360, 362-363.

Borges, B.C., Souza-Junior, E.J., da Costa, G., et al., 2013. Effect of dentin pre-treatment with a casein phosphopeptideamorphous calcium phosphate (CPP-ACP) paste on dentin bond strength in tridimensional cavities. Acta Odontol. Scand., 71(1):271-277. [doi:10.3109/00016357.2012.671 364]

Cadenaro, M., Antoniolli, F., Sauro, S., et al., 2005. Degree of conversion and permeability of dental adhesives. Eur. J. Oral Sci., 113(6):525-530. [doi:10.1111/j.1600-0722. 2005.00251.x]

Dabsie, F., Gregoire, G., Sharrock, P., 2012. Critical surface energy of composite cement containing MDP (10methacryloyloxydecyl dihydrogen phosphate) and chemical bonding to hydroxyapatite. J. Biomater. Sci.Polym. Ed., 23(1-4):543-554. [doi:10.1163/092050611X 554480]

de Munck, J., van Meerbeek, B., Yoshida, Y., et al., 2003. Four-year water degradation of total-etch adhesives bonded to dentin. J. Dent. Res., 82(2):136-140. [doi:10. 1177/154405910308200212]

Denner, N., Heydecke, G., Gerds, T., et al., 2007. Clinical comparison of postoperative sensitivity for an adhesive resin cement containing 4-META and a conventional glass-lonomer cement. Int. J. Prosthodont, 20(1):73-78.

Geiger, S., Matalon, S., Blasbalg, J., et al., 2003. The clinical effect of amorphous calcium phosphate (ACP) on root surface hypersensitivity. Oper. Dent., 28(5):496-500.

Giachetti, L., Scaminaci Russo, D., Rossi Campani, E., et al., 2011. Comparison of experienced and inexperienced operators on bond strengths of total-etch and self-etch bonding systems. Am. J. Dent., 24(5):271-276.

Giulio, A.B., Matteo, Z., Serena, I.P., et al., 2009. In vitro evaluation of casein phosphopeptide-amorphous calcium phosphate (CPP-ACP) effect on stripped enamel surfaces. A SEM investigation. J. Dent., 37(3):228-232. [doi:10. 1016/j.jdent.2008.11.015]

Inoue, S., Koshiro, K., Yoshida, Y., et al., 2005. Hydrolytic stability of self-etch adhesives bonded to dentin. J. Dent. Res., 84(12):1160-1164. [doi:10.1177/1544059105084 01213]

Iwai, H., Fujita, K., Ikemi, T., et al., 2013. Development of MDP-based one-step self-etch adhesive-effect of additional 4-META on bonding performance. Dent. Mater. J., 32(1):1-9. [doi:10.4012/dmj.2012-179]

Kanehira, M., Finger, W.J., Hoffmann, M., et al., 2006. Relationship between degree of polymerization and enamel bonding strength with self-etching adhesives. J. Adhes. Dent., 8(4):211-216.

Katsuno, K., Manabe, A., Itoh, K., et al., 1996. Contact dermatitis caused by 2-HEMA and GM dentin primer solutions applied to guinea pigs and humans. Dent. Mater. J., 15(1):22-30. [doi:10.4012/dmj.15.22]

Koibuchi, H., Yasuda, N., Nakabayashi, N., 2001. Bonding to dentin with a self-etching primer: the effect of smear layers. Dent. Mater., 17(2):122-126. [doi:10.1016/S01095641(00)00049-X]

Lin, J., Mehl, C., Yang, B., et al., 2010. Durability of four composite resin cements bonded to dentin under simulated pulpal pressure. Dent. Mater., 26(10):1001-1009. [doi:10.1016/j.dental.2010.06.004]

Lin, J., Kern, M., Ge, J., et al., 2013. Influence of peripheral enamel bonding and chlorhexidine pretreatment on resin bonding to dentin. J. Adhes. Dent., 15(4):351-359. [doi:10. 3290/j.jad.a29582]

Marshall, G.W.Jr., Marshall, S.J., Kinney, J.H., et al., 1997. The dentin substrate: structure and properties related to bonding. J. Dent., 25(6):441-458. [doi:10.1016/S03005712(96)00065-6]

Monticelli, F., Osorio, R., Mazzitelli, C., et al., 2008. Limited decalcification/diffusion of self-adhesive cements into dentin. J. Dent. Res., 87(10):974-979. [doi:10.1177/ 154405910808701012]

Oliveira, S.S., Pugach, M.K., Hilton, J.F., et al., 2003. The influence of the dentin smear layer on adhesion: a self-etching primer vs. a total-etch system. Dent. Mater., 19(8):758-767. [doi:10.1016/S0109-5641(03)00023-X]

Ommerborn, M.A., Schneider, C., Giraki, M., et al., 2007. In vivo evaluation of noncarious cervical lesions in sleep bruxism subjects. J. Prosthet. Dent., 98(2):150-158. 
[doi:10.1016/S0022-3913(07)60048-1]

Osborne-Smith, K.L., Burke, F.J., Wilson, N.H., 1999. The aetiology of the non-carious cervical lesion. Int. Dent. J., 49(3):139-143. [doi:10.1002/j.1875-595X.1999.tb00898.x]

Oshiro, M., Yamaguchi, K., Takamizawa, T., et al., 2007. Effect of CPP-ACP paste on tooth mineralization: an FE-SEM study. J. Oral Sci., 49(2):115-120. [doi:10.2334/ josnusd.49.115]

Paranjpe, A., Bordador, L.C., Wang, M.Y., et al., 2005. Resin monomer 2-hydroxyethyl methacrylate (HEMA) is a potent inducer of apoptotic cell death in human and mouse cells. J. Dent. Res., 84(2):172-177. [doi:10.1177/ 154405910508400212]

Pashley, D.H., Livingstone, M.J., Greenhill, J.D., 1978. Regional resistances to fluid flow in human dentine in vitro. Arch. Oral Biol., 23(9):807-810. [doi:10.1016/0003-9969 (78)90159-0]

Pashley, D.H., Mattews, W.G., Zhang, Y., 1996. Fluid shifts across human dentin in vitro in response to hydrodynamic stimuli. Arch. Oral Biol., 41(11):1065-1072. [doi:10. 1016/S0003-9969(96)00059-3]

Pashley, D.H., Tay, F.R., Haywood, V.B., et al., 2008. Consensus-based recommendations for the diagnosis and management of dentin hypersensitivity. Comp. Cont. Educ. Dent., 29(1):1-7.

Perdigao, J., Gomes, G., Gondo, R., et al., 2006. In vitro bonding performance of all-in-one adhesives. Part I: microtensile bond strengths. J. Adhes. Dent., 8(6):367-373.

Piekarz, C., Ranjitkar, S., Hunt, D., et al., 2008. An in vitro assessment of the role of Tooth Mousse in preventing wine erosion. Aust. Dent. J., 53(1):22-25. [doi:10.1111/ j.1834-7819.2007.00003.x]

Que, K., Ruan, J., Fan, X., et al., 2010. A multi-centre and cross-sectional study of dentine hypersensitivity in China. J. Clin. Periodontol., 37(7):631-637. [doi:10.1111/j. 1600-051X.2009.01513.x]

Rahiotis, C., Vougiouklakis, G., 2007. Effect of a CPP-ACP agent on the demineralization and remineralization of dentine in vitro. J. Dent., 35(8):695-698. [doi:10.1016/ j.jdent.2007.05.008]

Ramalingam, L., Messer, L.B., Reynolds, E.C., 2005. Adding casein phosphopeptide-amorphous calcium phosphate to sports drinks to eliminate in vitro erosion. Pediatr. Dent., 27(1):61-67.

Ranjitkar, S., Rodriguez, J.M., Kaidonis, J.A., et al., 2009. The effect of casein phosphopeptide-amorphous calcium phosphate on erosive enamel and dentine wear by toothbrush abrasion. J. Dent., 37(4):250-254. [doi:10.1016/ j.jdent.2008.11.013]

Reynolds, E.C., 1997. Remineralization of enamel subsurface lesions by casein phosphopeptide-stabilized calcium phosphate solutions. J. Dent. Res., 76(9):1587-1595. [doi:10.1177/00220345970760091101]

Reynolds, E.C., 1998. Anticariogenic complexes of amorphous calcium phosphate stabilized by casein phosphopeptides: a review. Spec. Care Dent., 18(1):8-16. [doi:10. 1111/j.1754-4505.1998.tb01353.x]

Rimondini, L., Baroni, C., Carrassi, A., 1995. Ultrastructure of hypersensitive and non-sensitive dentine. A study on replica models. J. Clin. Periodontol., 22(12):899-902. [doi:10.1111/j.1600-051X.1995.tb01792.x]

Sano, H., Shono, T., Sonoda, H., et al., 1994. Relationship between surface area for adhesion and tensile bond strength - evaluation of a micro-tensile bond test. Dent. Mater., 10(4):236-240. [doi:10.1016/0109-5641(94)90067-1]

Sattabanasuk, V., Burrow, M.F., Shimada, Y., et al., 2009. Resin bonding to dentine after casein phosphopeptideamorphous calcium phosphate (CPP-ACP) treatments. $J$. Adhes. Sci. Technol., 23(7-8):1149-1161. [doi:10.1163/ 156856109X432686]

Sauro, S., Mannocci, F., Toledano, M., et al., 2009. EDTA or $\mathrm{H}_{3} \mathrm{PO}_{4} / \mathrm{NaOCl}$ dentine treatments may increase hybrid layers' resistance to degradation: a microtensile bond strength and confocal-micropermeability study. J. Dent., 37(4):279-288. [doi:10.1016/j.jdent.2008.12.002]

Sauro, S., Toledano, M., Aguilera, F.S., et al., 2010. Resindentin bonds to EDTA-treated vs. acid-etched dentin using ethanol wet-bonding. Dent. Mater., 26(4):368-379. [doi:10.1016/j.dental.2009.12.008]

Silva-Júnior, C.A., Borges, B.C., Souza-Júnior, E.J., et al., 2011. Effect of CPP-ACP treatment on dentin bondstrength of self-etching adhesives. Dent. Mater., 27(3): $1-84$.

Simonetti, M., Radovic, I., Vano, M., et al., 2006. The influence of operator variability on adhesive cementation of fiber posts. J. Adhes. Dent., 8(6):421-425.

Sulieman, M., 2005. An overview of bleaching techniques: 2. Night Guard Vital Bleaching and non-vital bleaching. Dent. Update, 32(1):39-40, 42-34, 46.

Swift, E.J., 2004. Causes, prevention, and treatment of dentin hypersensitivity. Comp. Cont. Educ. Dent., 25(2):95-106, 109.

Tani, C., Finger, W.J., 2002. Effect of smear layer thickness on bond strength mediated by three all-in-one self-etching priming adhesives. J. Adhes. Dent., 4(4):283-289.

Tantbirojn, D., Huang, A., Ericson, M.D., et al., 2008. Change in surface hardness of enamel by a cola drink and a CPP-ACP paste. J. Dent., 36(1):74-79. [doi:10.1016/j. jdent.2007.10.008]

Tay, F.R., Pashley, D.H., 2002. Dental adhesives of the future. J. Adhes. Dent., 4(2):91-103.

Tay, F.R., Pashley, D.H., Suh, B.I., et al., 2002. Single-step adhesives are permeable membranes. J. Dent., 30(7-8): 371-382. [doi:10.1016/S0300-5712(02)00064-7]

Tokiwa, O., Park, B.K., Takezawa, Y., et al., 2008. Relationship of tooth grinding pattern during sleep bruxism and dental status. Cranio, 26(4):287-293.

Tsuchimoto, Y., Yoshida, Y., Mine, A., et al., 2006. Effect of 4-MET- and 10-MDP-based primers on resin bonding to titanium. Dent. Mater. J., 25(1):120-124. [doi:10.4012/ dmj.25.120]

Tyas, M.J., 1995. The Class V lesion—aetiology and restoration. 
Aust. Dent. J., 40(3):167-170. [doi:10.1111/j.1834-7819. 1995.tb05631.x]

van Landuyt, K.L., Snauwaert, J., Peumans, M., et al., 2008. The role of HEMA in one-step self-etch adhesives. Dent. Mater., 24(10):1412-1419. [doi:10.1016/j.dental.2008. 02.018]

van Landuyt, K.L., de Munck, J., Mine, A., et al., 2010. Filler debonding \& subhybrid-layer failures in self-etch adhesives. J. Dent. Res., 89(10):1045-1050. [doi:10.1177/ 0022034510375285]

Vanuspong, W., Eisenburger, M., Addy, M., 2002. Cervical tooth wear and sensitivity: erosion, softening and rehardening of dentine; effects of $\mathrm{pH}$, time and ultrasonication. J. Clin. Periodontol., 29(4):351-357. [doi:10. 1034/j.1600-051X.2002.290411.x]

West, N., Addy, M., Hughes, J., 1998. Dentine hypersensitivity: the effects of brushing desensitizing toothpastes, their solid and liquid phases, and detergents on dentine and acrylic: studies in vitro. J. Oral Rehabil., 25(12):885-895. [doi:10.1046/j.1365-2842.1998.00339.x]
Yamaguchi, K., Miyazaki, M., Takamizawa, T., et al., 2007. Ultrasonic determination of the effect of casein phosphopeptide-amorphous calcium phosphate paste on the demineralization of bovine dentin. Caries Res., 41(3): 204-207. [doi:10.1159/000099319]

Yang, B., Ludwig, K., Adelung, R., et al., 2006. Micro-tensile bond strength of three luting resins to human regional dentin. Dent. Mater., 22(1):45-56. [doi:10.1016/j.dental. 2005.02.009]

Yoshida, Y., Nagakane, K., Fukuda, R., et al., 2004. Comparative study on adhesive performance of functional monomers. J. Dent. Res., 83(6):454-458. [doi:10.1177/ 154405910408300604]

Zorba, Y.O., Erdemir, A., Ercan, E., et al., 2010. The effects of three different desensitizing agents on the shear bond strength of composite resin bonding agents. J. Mech. Behav. Biomed. Mater., 3(5):399-404. [doi:10.1016/ j.jmbbm.2010.03.003]

\section{中文穊要:}

本文题目: 酪蛋白磷酸肽-无定形磷酸钲、不同玷污层的处理和储存时间对牙本质粘接的影响

Influence of casein phosphopeptide-amorphous calcium phosphate application, smear layer removal, and storage time on resin-dentin bonding

研究目的：评价含有酪蛋白磷酸肽-无定形磷酸钙（CPP-ACP）的再矿化剂Tooth Mousse（TM）的使用、 不同站污层的处理以及样本储存时间对牙本质粘接微拉伸性能的影响。

研究方法: 将牙本质样本分成保留玷污层组和用 $15 \%$ 乙二胺四乙酸 (EDTA) 处理 90 秒去除玷污层组。每 组根据是否使用TM处理再分亚组。每个亚组分别用三种不同的粘结剂 (两步法自酸蚀Clearfil SE Bond（CSE）、一步法自酸蚀G-Bond（GB）和全酸蚀Adper Single Bond 2（SB））与牙本 质样本粘接, 分别经过 3 天和 6 个月的去离子水储存。样本进行切割微拉伸测试并通过扫描电 镜分析断裂界面模式。

重要结论: 经过再矿化剂TM预处理, 可以减少牙齿的敏感性, 并且对于这三种粘结系统经过长时间储存 后的粘结性能没有影响。EDTA的处理对于长期储存的粘结性能没有显著影响。额外的TM和 EDTA对短期（3天）粘接力会有效应，但对长期（6个月）的粘接力没有影响。

关键词组: 玷污层; 再矿化剂 Tooth Mousse; 微拉伸性能; 储存时间; 粘结剂 